\title{
As vivências artísticas como práticas de inclusão
}

\author{
Artistic experiences as inclusion practices \\ Experiencias artísticas como prácticas de inclusión
}

José Cavalcante Lacerda Junior

Professor doutor no Instituto Federal de Educação, Ciência e Tecnologia do Amazonas, Manaus, Amazonas, Brasil.

jose.cavalcante@ifam.edu.br

ORCID - http://orcid.org/0000-0001-9697-8377

\section{Maria Inês Gasparetto Higuchi}

Pesquisadora doutora no Instituto Nacional de Pesquisas da Amazônia, Manaus, Amazonas, Brasil. higuchi.mig@gmail.com

ORCID - http://orcid.org/0000-0001-6525-4018

Recebido em 19 maio 2020

Aprovado em 18 de setembro de 2020

Publicado em 26 de outubro de 2020

\section{RESUMO}

As vivências artísticas aglutinam um exercício afetivo no campo das artes. Por sua vez, observa-se nos últimos anos que os processos de inclusão cada vez mais ganham relevância em propostas de atendimento das crianças com deficiência. Imerso nessa conjuntura, como pensar processos de inclusão a partir das vivências artísticas realizadas por crianças com deficiência? De outra forma, de que maneira a arte se configura como um instrumento de inclusão? Articulado nessa perspectiva, esse artigo procura compreender de que maneira as vivências artísticas se constituem em processos inclusivos para as crianças com deficiência. $\mathrm{O}$ lócus de realização da pesquisa é o Liceu de Artes e Ofícios Claudio Santoro, na cidade de Manaus, Amazonas. Para este estudo foi analisado os relatórios de atividades da instituição voltados para a inclusão, entre 2015-2018, além da observação participante realizada no mesmo período. Os resultados obtidos a partir da aplicação da análise de conteúdo sinalizam que as vivências artísticas ao considerar as crianças com deficiência em suas diferenças, em suas socializações, em suas apropriações da cidade, perpassam relações de constantes reorganizações. Esse processo promove o reordenamento dos espaços físicos e adaptações curriculares, os quais sinalizam para um exercício flexível de ações psicopedagógicas que visam permitir a presença dessas crianças em suas atividades institucionais.

Palavras-chave: Artes; inclusão; crianças.

\section{ABSTRACT}

Artistic experiences bring together an affective exercise in the field of the arts. In turn, it has been observed in recent years that the inclusion processes increasingly gain relevance in proposals for the care of children with disabilities. Immersed in this conjuncture, how to think about inclusion processes from the artistic experiences carried out by children with disabilities? Otherwise, how is art configured as an instrument of inclusion? Articulated in this perspective, this article seeks to understand how artistic experiences constitute inclusive processes for children with disabilities. The locus of the research is the Liceu de Artes e Ofícios Claudio Santoro, in the city of Manaus, Amazonas. 
For this study, the institution's activity reports focused on inclusion between 2015-2018 were analyzed, in addition to the participant observation carried out in the same period. The results obtained from the application of the content analysis indicate that the artistic experiences when considering children with disabilities in their differences, in their socializations, in their appropriations of the city, permeate relationships of constant reorganizations. This process promotes the reorganization of physical spaces and curricular adaptations, which signal for a flexible exercise of psychopedagogical actions that aim to allow the presence of these children in their institutional activities.

Keywords: Arts; inclusion; children.

\section{RESUMEN}

Las experiencias artísticas reúnen un ejercicio afectivo en el campo de las artes. A su vez, se ha observado en los últimos años que los procesos de inclusión adquieren cada vez más relevancia en las propuestas para el cuidado de niños con discapacidades. Inmerso en esta coyuntura, ¿cómo pensar en los procesos de inclusión a partir de las experiencias artísticas realizadas por niños con discapacidad? De lo contrario, ¿cómo se configura el arte como instrumento de inclusión? Articulado en esta perspectiva, este artículo busca comprender cómo las experiencias artísticas constituyen procesos inclusivos para niños con discapacidades. El lugar de la investigación es el Liceu de Artes e Ofícios Claudio Santoro, en la ciudad de Manaus, Amazonas. Para este estudio, se analizaron los informes de actividad de la institución centrados en la inclusión entre 2015-2018, además de la observación participante realizada en el mismo período. Los resultados obtenidos de la aplicación del análisis de contenido indican que las experiencias artísticas al considerar a los niños con discapacidad en sus diferencias, en sus socializaciones, en sus apropiaciones de la ciudad, impregnan las relaciones de reorganizaciones constantes. Este proceso promueve la reorganización de los espacios físicos y las adaptaciones curriculares, que indican un ejercicio flexible de acciones psicopedagógicas que tienen como objetivo permitir la presencia de estos niños en sus actividades institucionales.

Palabras clave: Letras; inclusión; niños.

\section{Introdução}

Reconhecer o universo infantil não é apenas uma sentença reflexiva que postula um "lugar" teórico em alguma Ciência. Ao contrário, diz de uma postura política que aponta diferentes maneiras de refletir os desafios da atual sociedade e construir outros "olhares". Desde as complexas questões individuais/subjetivas até as urgências das temáticas socioambientais, visibilizar e ouvir as crianças configura-se como pauta irrevogável para problematizar o cenário contemporâneo (SARMENTO, 2019).

Verifica-se que boa parte dos lugares que as crianças circulam cotidianamente nas cidades são projetados pelos adultos (CHRISTENSEN; O’BRIEN, 2003; RASMUSSEM, 2004; LUZ; KUHNEN, 2013). Um desses espaços representativos é a escola, onde se tem majoritariamente a presença infantil. Há escolas formais e escolas alternativas de educação 
http://dx.doi.org/10.5902/1984686X44380

para criança e adolescentes. Em ambos os espaços, a arte é um ofício que transversa o currículo fundamentado nas áreas de conhecimento. Em alguns casos a arte é central na determinação de atividades e, por intermédio dela, o educando ou educanda se expressa para conviver na sociedade em que está engajada.

Em Manaus, Capital do Estado do Amazonas, isso acontece em alguns espaços, sendo um exemplo o Liceu de Artes e Ofícios Claudio Santoro. Como instituição, o Liceu está vinculado à Secretaria de Estado de Cultura e Economia Criativa e desenvolve diversas vivências artísticas nas áreas da dança, música, teatro e artes visuais para crianças e adolescentes. É nesse ambiente que esse público tem oportunidade de participar de experiências de inclusão num mundo pouco permeável, seja para quem tem poucos recursos sociais e econômicos, seja para as pessoas com deficiência.

Com efeito, os processos de inclusão desencadearam, nas últimas décadas, relevantes papeis de colaboração em propostas de atendimento das pessoas, em especial das crianças com deficiência, em unidades escolares. Apesar de persistentes perspectivas que segregam, marginalizam ou promovam o assistencialismo ainda presentes no imaginário dessa discussão, iniciativas de inclusão têm se tornado relevantes (TROCOLI; BONFATTI, 2018).

Desde a constituição do texto legal da Declaração Universal dos Direitos das Crianças, em 1959, cujos postulados inspiraram a elaboração do Estatuto da Criança e do Adolescente - ECA (BRASIL, 1990), o lugar das crianças na sociedade, interpreta e consagra os direitos fundamentais à infância. A criança passa a ser vista não apenas como objeto de proteção, mas como titular de um conjunto de direitos civis e políticos. As crianças são dignas de proteção da sociedade, a qual lhes deve fornecer plenos meios de promoção do desenvolvimento integral, como a educação escolar.

No âmbito educativo, o século XX marca, ainda, os fundamentos da necessidade de inclusão. Um desses marcos é Conferência Mundial sobre Educação para Todos, em Jomtien na Tailândia, em 1990, onde a educação é concebida com o direito fundamental, realocando a questão educativa para o centro das discussões, destacando a importância e prioridade para a educação básica (UNESCO, 1990).

Essa perspectiva aponta para a necessidade de construir garantias básicas de aprendizagem mediante a inclusão de todos. Essa é conjuntura que pauta a Declaração de Salamanca realizada na Espanha, em 1994, onde é apontado o direito que todas as pessoas à educação, independentemente de suas diferenças particulares. Nessa 
http://dx.doi.org/10.5902/1984686X44380

declaração fica patente a ideia de que integração escolar, não é apenas uma medida em si, mas procura garantir a universalização do acesso à educação para todos. A Declaração de Salamanca dá "prioridade política e financeira para o aprimoramento de seus sistemas educacionais no sentido de se tornarem aptos a incluírem todas as crianças, independentemente de suas diferenças ou dificuldades individuais" (ESPANHA, 1994, p. 10).

Conforme se verifica, o processo de inclusão atravessa o escopo da Educação. Isso significa um avanço, pois consagra um princípio fundamental presente nas mais diversas democracias. No Brasil, por exemplo, a educação passa a ser explicitamente um direito de todos (BRASIL, 1988). No entanto, essa relação, por vezes, pode ocasionar algumas confusões, uma vez que a inclusão traz em seu sentido uma diversidade de situações que perpassam desde a vulnerabilidade social até situações neuropsicológicas (CAMARGO, 2017). Para não incorrer nessa situação, o texto em cena destaca de forma específica a inclusão de crianças com deficiência.

No Brasil, após adequar-se às metodologias estatísticas, há uma correção na margem de corte do último censo, 2010, pelo Instituto Brasileiro de Geografia e Estatística - IBGE, que reduziu de 23,9\% da população com alguma deficiência para 6,7\% (SIMÕES; ATHIAS; BOTELHO, 2018). Esses sujeitos, no âmbito educativo, estão inseridos no Plano Nacional de Educação, que destaca:

O poder público buscará ampliar o escopo das pesquisas com fins estatísticos de forma a incluir informação detalhada sobre o perfil das populações de 4 a 17 anos com deficiência.

[...] Estratégia 4.15. Promover, por iniciativa do Ministério da Educação (MEC), nos órgãos de pesquisa, demografia e estatística competentes, a obtenção de informação detalhada sobre o perfil das pessoas com deficiência, transtornos globais do desenvolvimento e altas habilidades ou superdotação de 0 a 17 anos. (BRASIL, 2014, s./p.).

Imersos nesse contexto, como pensar processos de inclusão a partir das vivências artísticas realizadas por crianças com deficiência? De outra forma, de que maneira a arte se configura como um instrumento de inclusão no ambiente educativo? Articulado nessa perspectiva, este o artigo procura compreender de que maneira as vivências artísticas se constituem em processos inclusivos para as crianças com deficiência.

Para este estudo analisamos os relatórios de atividades da instituição voltados para a inclusão, entre 2015-2018, além da observação participante (PIRES, 2007; AZEVEDO; BETTI, 2014) realizada no mesmo período. Os resultados obtidos a partir da aplicação da 
http://dx.doi.org/10.5902/1984686X44380

Análise de Conteúdo (BARDIN, 2016) permitiram a estruturação de duas macro-categorias dos processos de inclusão das crianças: (1) a logística e (2) as vivências.

\section{A logística de inclusão no Liceu}

O Liceu de Artes e Ofícios Claudio Santoro configura-se como espaço de encontro e construção de processos inclusivos. Enquanto política pública, inserida no âmbito da cultura, o Liceu articula-se como espaço de formação em artes (AMAZONAS, 2007), a qual corresponde a um conjunto de estratégias focadas na expressão artística que busca essencialmente a formação técnica, a fruição estética e o desenvolvimento de aspectos criativos.

O Liceu é, assim, um ambiente educativo e como tal, abre-se ao intercâmbio de inúmeras possibilidades, como o contato das crianças por intermédio de suas vivências artísticas com os vários espaços da cidade e, principalmente, com os equipamentos culturais como praças, centros culturais, teatros, museus e bibliotecas (LACERDA JUNIOR, 2018). O Liceu está organizado em dois eixos: o pedagógico e o artístico.

O eixo pedagógico curricular, no qual o processo didático-pedagógico está organizado. Conta com pedagogos e técnicos educacionais, como professores, fiscal escolar, bibliotecário, profissional de instrumentoteca e montador de orquestras. O eixo artístico é o responsável pela implementação técnica e de produção, tendo uma coordenação artística dos núcleos, composto por técnicos com formação artística que orientam as especificidades de cada segmento.

No que diz respeito à inclusão das crianças com deficiência, o Liceu desenvolve serviços de acessibilidade tanto de crianças quanto de adultos, através dos seus cursos, como dança para cadeirantes e coral de surdos, por exemplo. Há ainda uma biblioteca braile com equipamentos que produzem e reproduzem obras literárias para cegos.

Observa-se que através de suas modalidades artísticas (dança, teatro, música e artes visuais) estimulam o indivíduo a manifestar e/ou aprimorar seu fazer artístico. Nesse processo de desenvolvimento, as dimensões - social, cognitiva e afetiva - perpassam o processo e estão incluídas, expressando-se pelo exercício da disciplina, da atenção concentrada, da autonomia, da autoestima, da comunicação e relacionamento interpessoal.

A inserção das crianças a partir de uma logística de inclusão ocorre fundamentalmente através do setor Psicossocial. Esse setor é formado por profissionais da Psicologia e Serviço Social, que serve como "porta de entrada" para o acolhimento e integração de 
http://dx.doi.org/10.5902/1984686X44380

crianças a idosos nas atividades disponibilizadas pelo Liceu. Esse setor atua integrado às outras áreas, como a de Pedagogia, a partir de duas frentes ativas. A primeira diz respeito aos atendimentos que têm por finalidade promover serviços e ações relativas à promoção de saúde e de aprendizagem para indivíduos ou grupos.

O atendimento não se reveste do caráter clínico ou psicoterapêutico, mas como acolhimento que visa subsidiar alternativas de melhoria na articulação ensinoaprendizagem, bem como encaminhamentos para a rede de saúde pública (Sistema Único de Saúde - SUS). Esses atendimentos organizam-se em três tipos. No primeiro, Saúde Mental com a inclusão das Pessoas Com Deficiência (PCD’s), com transtorno ou com síndromes que demandem atenção junto às atividades educativas; No segundo, Processo Ensino-Aprendizagem, que enfoca relações emergentes na interface arte-educador e educando, como verbalizações, gestos ou comportamentos que possam interferir no processo de empatia; Por fim, a Assistência Social, a qual trata de situações que necessitem auxílio em situações de risco, vulnerabilidade ou outras demandas dos alunos, educadores e colaboradores.

$\mathrm{Na}$ segunda frente, encontra-se o acompanhamento ensino-aprendizagem que busca auxiliar o processo educativo por intermédio de intervenções que possam subsidiar a relação dos educandos com os processos artísticos. Esse procedimento ocorre a partir de duas maneiras, destacadas nos pontos a seguir:

1) Formação Continuada dos arte-educadores: encontros semestrais, jornada pedagógica (primeiro semestre) e semana de planejamento (segundo semestre), para auxiliar nas discussões teóricas e metodológicas acerca de temas que atravessam a educação contemporânea;

2) Atividades Psicopedagógicas aos educandos: palestras, oficinas e rodas de conversas com os educandos acerca de temas do cotidiano e da educação.

Esse setor de acompanhamento busca, ainda, construir uma rede de atendimento e apoio para professores e demais técnicos, juntamente com o núcleo de pedagogia, nas dificuldades provenientes do ensino-aprendizagem, além do apoio com os familiares.

Nota-se que nos últimos anos tem ocorrido uma intensificação e procura pelo Liceu para a inserção de crianças em práticas inclusivas por intermédio da arte. Conforme os relatórios de atendimento, no ano de 2015 foram atendidas 42 crianças, enquanto no ano de 2018 registrou-se o atendimento de 95 crianças. Tais números refletem uma média captável pelo registro do Setor Psicossocial uma vez que o acesso das crianças com 
http://dx.doi.org/10.5902/1984686X44380

deficiência ao Liceu se dá, basicamente, por duas vias: 1) indireta: quando as crianças são encaminhadas por profissionais de outras instituições (principalmente escolas públicas) ou serviços de saúde onde já realizam algum tipo de acompanhamento; e 2) direta: realizado por matrículas diretas organizadas pela direção, geralmente, no início de cada semestre do ano letivo.

Observou-se que essa procura ocorre, basicamente, pela falta de outros espaços com essa finalidade na cidade, principalmente, para as crianças com menor poder aquisitivo. Tal contexto não é exclusivo para inclusão em atividades psicossociais. Quando se observa o cenário da educação inclusiva formal, a oferta é precária seja no âmbito da cidade de Manaus (MATOS; SOUZA; OLIVEIRA, 2019), seja quando se observa o índice de acesso à educação básica de pessoas com deficiência, 4 a 17 anos, no Estado do Amazonas, onde se registra o menor nível entre os estados, 75,5\%, sendo menor inclusive que a média nacional, 82\% (INEP, 2019).

Essa perspectiva, reverbera a ausência de políticas públicas voltadas para essa parte da população. Em Manaus, destaca-se uma singularidade quando se observa o processo de inclusão pela ótica da vulnerabilidade social de crianças e adolescentes. Nota-se que o Estado transfere ao âmbito não-governamental (abrigos, por exemplo) sua responsabilidade (VASCONCELOS, 2015).

Com efeito, a insuficiência para a crescente demanda de acolhimento das crianças com deficiência traz o aspecto da regulação do acesso por meio de diagnósticos e laudos. A influência do modelo biomédico, ainda se observa, quando a construção de diagnósticos e laudos é o instrumento que autoriza a presença nas instituições (MOYSÉS; COLARES, 2013). O acesso é vinculado ao saber médico cujo laudo é o instrumento que válida a inclusão no processo (FANIZZI, 2017).

Nesse cenário, o aspecto patológico antecede a criança em si, isto é, primeiro se acolhe o transtorno e o reconhece depois a criança como se fosse possível fazer uma dissociação de tais aspectos. O que se observa nessa conjuntura, é um cenário cada vez psicopatologizado, que para existir necessita credenciar o "encaixe" de sinais e sintomas em quadros clínicos padronizados (FANIZZI, 2017). Corre-se, dessa forma, o risco de produzir enquadres que, por vezes, estigmatizam uma condição e dispensar intersecções profissionais de outras áreas que vislumbrem outras alternativas.

Como uma "moldura psicopatológica", o laudo enquadra a criança em procedimentos e técnicas a serem manejados a partir de então para o seu tratamento. Nota-se, ainda, a 
http://dx.doi.org/10.5902/1984686X44380

consagração do modelo biomédico como abordagem de entendimento das especificidades de cada criança, apesar de o Estatuto da Pessoa com Deficiência (BRASIL, 2015) preconizar uma abordagem de avaliação multiprofissional e interdisciplinar (SIMÕES, ATHIAS; BOTELHO, 2018).

Outro aspecto a ser destacado é a escassez de atendimento para as não-crianças. Embora não seja o foco deste artigo, vale destacar que a carência de instituições de atendimento fica mais acentuada para aqueles entre 12 a 18 anos, quando sinais e sintomas demandam principalmente atividades de socialização e ocupacionais.

O "apelo" emocional para os atendimentos e acolhimentos não prossegue quando a criança entra na adolescência e na juventude. Nessa conjuntura, a escola formal é o último reduto de acolhimento. No entanto, observa-se uma exclusão de dentro (BEZERRA, 2017), uma vez que o processo de inclusão se demonstra classificatório e reprodutor de desigualdades existentes no bojo dos atores escolares.

Com efeito, nota-se que crianças diagnosticadas com Autismo, Transtorno de Déficit de Atenção e Hiperatividade - TDAH, Síndrome de Down e Retardo Mental são as que mais demandam esse fluxo de acompanhamento no Liceu. O motivo para tanto, de modo geral, é a percepção que as atividades artísticas podem colaborar na potencialização do desempenho físico, cognitivo e social, como na música por exemplo (COSTA et al., 2011).

Essa percepção encontra ressonância em estudos com evidências científicas que habilitam as áreas da arte em contexto clínico-terapêutico, como a arteterapia (CIORNAI, 2005; VIEIRA, 2017), a musicoterapia (NOGUEIRA, 2003; FONSECA et al.,2006; TONDATTI, 2011; SANTOS, CAVALCANTE, SILVA JUNIOR, 2019), a dançaterapia (GARÇÃO, 2011; TEIXEIRA-MACHADO, 2015), etc. Outrossim, a ressonância dessa perspectiva no Liceu é um desafio à medida que o mesmo não se configura como uma escola clínica ou escola especializada em acompanhamento terapêutico, mas é uma escola livre de artes.

Essa situação emerge e necessita ser dialogada nos primeiros momentos de acolhimento das crianças junto com os pais e os profissionais que encaminham. Mas, fundamentalmente, é um diálogo contínuo com os arte-educadores. A presença das crianças com deficiência conta com participação dos arte-educadores. Isso não significa que o processo seja natural ou não exija esforço e diálogo para entendimento das singularidades que a demanda possui. 
http://dx.doi.org/10.5902/1984686X44380

Parte desses profissionais estão vinculados à instituição por notório saber e outra parte advém de uma formação universitária. Observa-se que ambas situações 0 aprendizado para lidar com os processos inclusivos, de forma específico com os PCD's, ocorre na prática do fazer. Mesmo com a formação universitária, por intermédio dos cursos de licenciatura, a sensação de despreparo, seja teórico seja técnico, é premente (VITALINO, 2007; ARAÚJO, et al, 2010).

Daí a relevância da formação contínua através de oficinas, rodas de conversas, encontro com os pais, para que a circulação de informações, conhecimentos e técnicas que possam auxiliar na construção de vivências mais inclusivas. Outrossim, o acolhimento das crianças em processo de inclusão está organizado em quatro núcleos de atividades: dança, teatro, artes visuais e música.

Identifica-se na música, o núcleo com o maior quantitativo de crianças no processo inclusivo. Essa razão se dá, fundamentalmente, por duas razões: o núcleo de música possui o maior número de alunos matriculados e a maior diversidade de cursos, os quais podem ser realizados em grupo (como as orquestras) quanto individualmente (como as aulas de instrumentos violão, violino, piano etc.). Essa diversidade, de frequentadores e de cursos, possibilita ao núcleo de música a identificação de distintos manejos e experiências.

O núcleo de dança, por sua vez, destaca-se pela especificidade de seu fazer, que exige habilidades motoras e físicas. Para os processos de inclusão o esforço tem sido nessa direção, isto é, desenvolver práticas e metodologias que oportunizem, crianças com deficiência motora, por exemplo, a participarem das atividades e possam estar inseridos em suas vivências.

Verifica-se, ainda, a adesão aos cursos de artes visuais e teatro. No caso de artes visuais as atividades são mais estáticas e envolvem desenho, pintura, colagem, e oficinas que favorecem principalmente a participação de crianças que querem potencializar a atenção e a criatividade. Nos casos de teatro, as atividades exigem maior disciplina e interação possibilitando vínculos que podem favorecer a concentração e a socialização, como em casos específicos de autismo.

Assim, o Liceu se constitui como um espaço de encontros não somente de temáticas - artes, educação e processo inclusivo, mas de pessoas em diversos papeis e funções sociais. Essas pessoas com idades diferenciadas e múltiplos fazeres se encontram e vivenciam experiências com linguagens próprias de expressar o mundo através de oficinas, 
http://dx.doi.org/10.5902/1984686X44380

workshops, palestras, visitações, mostras culturais e mostras artísticas. A logística existente nesse processo permite que vivências artísticas de inclusão efetivamente se realizem.

\section{As vivências artísticas no processo de inclusão}

A linguagem é um instrumento facilitador de comunicação, mas não somente isso. Pela linguagem o indivíduo se imagina e expressa o mundo, projetando-se como algo que pertence ao seu próprio modo de ser. O indivíduo se compreende dentro de um processo interpretativo que se constitui pela linguagem (HERMANN, 2002). A linguagem torna a pessoa um ser pertencente a um mundo de relações que a permite desvendar e compreender a realidade.

As linguagens se diversificam nas mais distintas formas, seja a narrativa, a projetiva, a interpretativa, a plástica, a artística, etc. Nos interessa especialmente as vivências artísticas como linguagem que dão voz e abraçam a criança. As vivências artísticas como linguagem viva se constituem como uma faculdade ou habilidade em compreender aquilo que está ao seu redor (LACERDA JUNIOR; HIGUCHI, 2019) e como uma maneira de leitura do mundo (SCHROEDER, 2012).

As vivências artísticas, portanto, não se constituem como mero entretenimento, apesar de também o serem. As vivências artísticas ultrapassam o entretenimento para potencializar a função estética e comunicar o lugar do sujeito no mundo. E essa forma uma expressão do mundo é uma construção de si. Ao vivenciar as expressividades artísticas, a criança não somente participa de um modo de compreender o mundo, como se constitui nesse processo.

Ancorando-se nos processos simbólicos presentes nessa trajetória, pode-se dizer que essa interação e a forma como cada criança a experimenta, mobiliza-se a si mesmo. Vivenciar a arte comunica o mundo e mobiliza conjunturas pessoais do sujeito (SCHROEDER, 2012). E aqui reside a relevância das vivências artísticas no processo de inclusão.

Conhecer os aspectos presentes nas vivências artísticas como elementos de inclusão sinaliza à criança reconhecer seu estar no mundo. Sinaliza uma relação não estática, mas sempre aberta às variáveis que podem advir de um contexto mergulhado na intersubjetividade grupal. As intersubjetividades são partes fundantes da organização do seu estar no mundo. Destaca-se, portanto, alguns aspectos que as vivências artísticas 
http://dx.doi.org/10.5902/1984686X44380

podem contribuir no processo de inclusão: (1) no acolhimento das diferenças, (2) nas possibilidades de socialização, (3) no pertencimento à cidade, (4) nas redes de suporte.

\section{As vivências artísticas acolhem as diferenças}

Em sua própria dinâmica, a arte é diversa. As diversas expressões nas quais ela se constitui aglutina um mosaico de possibilidades e vivências a partir de múltiplas performances. As experiências em grupo ou individuais, seja no Liceu ou fora dele, projetam, desde a criatividade até a disciplina, possibilidades de autorregulação mediante a diferença.

A diferença, aqui, não como um exercício de tolerância ao outro e nem como uma correção de atitudes preconceituosas daqueles que acolhem, mas com uma produção social, onde as relações de poder e a transgressão favorecem a experimentação (SILVA, 2004). Essa conjuntura quebra a métrica da normalidade e abre-se ao mundo das possibilidades.

A rigor todos podem participar das atividades e as adequações vão se constituindo à medida que o processo ocorre. A expressividade desempenhada no teatro por determinada criança, por exemplo, pode não se constituir uma vivência exitosa na disciplina postural do manejo de um violino. A apresentação de palco do grupo de crianças no núcleo de dança pode solicitar a presença da mãe, que com o figurino solicitado, pode auxiliar e conjuntamente realizar a performance da criança com autismo.

A possibilidade de transitar e experimentar põe na essência das vivências artísticas realizadas pelas crianças uma autodescoberta e reconhecimento por parte dos demais (crianças, pais, arte-educadores) o que é possível ou não. As vivências artísticas acolhem as diferenças. Isso de forma alguma romantiza o processo. Há entraves, há dissensos, mas, fundamentalmente, há o reconhecimento da própria diferença que se recusa a fundirse com o idêntico (SILVA, 2004). Destaca-se que esse processo tem início no processo de acolhimento das crianças. Inicialmente, ocorre um atendimento, por vezes, acompanhado pelos responsáveis. Identifica-se as potencialidades de cada criança e indica-se, em conversa com os pais, as possibilidades de inclusão da criança em determinada vivência em um dos núcleos artísticos supracitados.

Nesse processo, é importante e necessário um tempo de experimentações, geralmente, os três primeiros meses, quando a criança é observada pelo arte-educador. Os responsáveis são orientados a verificar a dinâmica do processo. A interação entre crianças, 
com arte-educador, com responsáveis e com equipe psicossocial são essenciais para estabelecer um diálogo construtivo e claro acerca do processo. Tais elementos são importantes para vislumbrar a inclusão das crianças.

Dessa maneira, o reconhecimento da criança como ela efetivamente é, isto é, reconhecer suas diferenças, o período de experimentação (tempo de observação, testagens) e o diálogo entre os demais atores envolvidos possibilita a construção de processos inclusivos de acolhimento efetivo e afetivo das crianças. A inclusão não é uma realidade dada. É uma produção social (SILVA, 2004).

\section{As vivências artísticas oportunizam processos de socialização}

As crianças ao experimentarem a arte constroem contínuas elaborações sobre si e a realidade a sua volta (LACERDA JUNIOR; HIGUCHI, 2019). Para tanto, torna-se imprescindível a mediação realizada com o outro, isto é, em um contínuo processo de socialização. As vivências artísticas se inserem numa dinâmica inevitável de interações com o outro. Essa interação, por sua vez, provoca nas crianças além da participação a sua vinculação a um determinado grupo (GRIGOROWITSCHS, 2008).

$\mathrm{Na}$ interface com outras crianças e com adultos, inseridos em suas variadas representações (familiares, professores, artistas, por exemplo), as crianças com deficiência, ao participarem das vivências artísticas, encontram-se em processos de socialização que as oportunizam a constituição da realidade objetiva e do próprio sujeito (GRIGOROWITSCHS, 2008).

Durante a apresentação do coral infantil, por exemplo, é comum observar a dinâmica que antecede a apresentação: aquecimento vocal, repasse do repertório, posição no palco etc. Para além de toda a organização, a qual encontra seu ápice na apresentação, é muito comum observar as crianças em pequenos grupos. Seja em momentos de conversa, em encontros com as brincadeiras e em contato com adultos. As crianças "são, simultaneamente, atores sociais que interagem com adultos e outras crianças, ao mesmo tempo em que pertencem a uma forma de distinção social singular, a infância" (GRIGOROWITSCHS, 2008, p. 49).

Esse contexto torna-se mais significativo à medida em que as vivências artísticas expressas no Liceu conformam-se como socializações citadinas pautadas pela fruição estética e prazer. Embora as relações urbanas contemporâneas possam gerar medo e segregações (BAUMAN, 2001; 2009) e, no caso das crianças, um intenso investimento em 
ambientes supervisionados e seguros (MOLLO-BOUVIER, 2005; CARREIRA, 2016), as vivências artísticas evocam uma proximidade e contato mais direto com as crianças.

E ainda, se por um lado, a força das redes sociais e dos discursos pedagógicos estão cada vez mais voltados para uma pedagogia de auto-construção. Nota-se processos focados, exclusivamente, em aspectos cognitivistas, que isola o sujeito das relações proximais com outros, como a Homeschooling. Por outro lado, observa-se as vivências artísticas salientam o contato como momento de construção de maneiras de configurar a si e o outro.

O processo de socialização presente nas vivências artísticas é processo constituído nas relações de diversos elementos que exercitam o movimento, como a disciplina (conformada nos horários e exercícios/treinos específicos de cada curso, por exemplo), a execução das vivências (respeito e limites ao ritmo do outro), partilha do espaço físico, contato com o público etc. Enfim, as crianças interagem, mesmo determinadas em lugares específicos (GRIGOROWITSCHS, 2008) e participam ativamente de processos vividos (BELLONI, 2007).

\section{As vivências artísticas favorecem o pertencimento da criança na cidade}

A mediação com o espaço oportuniza maneiras singulares de perceber e de pertencer a ele. Ao circular pelos equipamentos culturais, antes pouco conhecidos ou pouco acessíveis, a criança percebe um mundo à sua disposição. Ao invés dos obstáculos, a permeabilidade (LOPES; FERNANDES, 2018). Isso significa que a reelaboração dos sentidos empregada pelas crianças não é encapsulada em uma lógica linear. Elas transitam em função de suas vivências. Quanto mais elas circulam, quanto mais elas se deslocam, quanto mais elas visitam os diferentes equipamentos culturais da cidade, mais intensa é a maneira de como elas reorganizam suas percepções e, consequentemente, reelaboram seu pertencimento a esse ambiente (LACERDA JUNIOR; HIGUCHI, 2019). É nesse vai-evem que, embora excluídos dos processos de decisões nas relações de construção da cidade, as crianças não deixam de desenvolver novos significados para a realidade e criar formas de se distanciarem da condição de exclusão (HIGUCHI; SILVA, 2013).

A vivência da arte é um importante instrumento para exprimir a relação das crianças com a cidade. As crianças ao vivenciarem a arte através do contato contínuo com as dinâmicas socioambientais da cidade reverberam uma linguagem de compreensão do 
http://dx.doi.org/10.5902/1984686X44380

mundo e seu próprio sentimento de pertença a esse mundo, bem como também se sentir pertencido em uma philia social (ARAÚJO, 2019).

A experiência da arte vinculada no Liceu transita do processo ensino-aprendizagem da sala de aula para um processo educativo com a cidade, para com aquilo que está ao seu redor. O conhecimento artístico transborda do ensino para um engajamento das interfaces que constituem o lugar da arte no mundo (LACERDA JUNIOR; HIGUCHI, 2019).

\section{As vivências artísticas criam redes de integração entre responsáveis}

Um elemento importante observado nos processos de inclusão a partir das vivências artísticas é a partilha e a criação de redes de informação e ajuda entre os responsáveis. Em outras palavras, o diálogo entre pais ou outros familiares das crianças participantes do processo, funciona como um espaço de vazão das dificuldades encontradas, mas, fundamentalmente, como canais de compartilhamento de endereços, ofertas de serviços, nomes de profissionais e outras instituições que podem auxiliar.

As vivências artísticas como práticas inclusivas não se constituem como espaços clínicos de atendimento, que buscam inexoravelmente tratar de um determinado transtorno. Ao contrário, oportunizam, minimamente, a presença das crianças em atividades desenvolvidas no âmbito das artes, constituindo-se como espaços de reverberação de uma polifonia de acolhimento mútuo acerca daquilo que é comum a todos: as dificuldades enfrentadas.

É muito comum escutar os relatos dos responsáveis do quão "pesado" e "desgastante" é o peso que as instituições colocam sobre eles. Quase sempre recordando que é o "papel da família" fazer isso ou aquilo. Se por um lado, há práticas que produzem uma naturalização do papel desempenhado pelos responsáveis é importante recordar que as relações produzidas na especificidade de cada criança com deficiência nem sempre reverbera um entendimento romântico ingênuo, mas atravessa um processo de ressignificação (FALKENBACH; DREXSLER; WERLER, 2008)

Daí a importância desse espaço de ressonância entre os responsáveis. Esse espaço assegura um momento de troca de informações, que pode incentivar o envolvimento dos mesmo com as situações que envolvem as singularidades que envolvem as crianças, bem como o engajamento em discussões que promovam uma maior articulação dos mesmos junto as práticas educacionais encontradas nas instituições (SILVEIRA; NEVES, 2006). 
Com efeito, o processo de inclusão configura-se como uma provocação (CAMARGO, 2017). Uma provocação para o ato educativo. Uma provocação a formação profissional. Uma provocação as instituições que produzam fazeres adequados às singularidades de seus sujeitos, nesse caso das crianças, em vez de esperar que uma determinada criança se ajustar a escola.

Assim, as vivências artísticas ao considerar as crianças com deficiência em suas diferenças, em suas socializações, em suas apropriações da cidade, perpassam relações de constantes reorganizações. Reordenamento dos espaços físicos e adaptações curriculares, por exemplo, devem promover um exercício flexível de ações psicopedagógicas que visam permitir a presença dessas crianças em suas atividades institucionais.

\section{Considerações}

Trazer o tema da inclusão para uma escola de artes é um desafio pedagógico e social. O desafio pedagógico se processa no fazer cotidiano das atividades de tal modo que todos, invariavelmente, tenham sua formação e acesso ao conhecimento garantido. Já o desafio social inclui assegurar os direitos e conquistas daqueles historicamente alijados. Tal exercício de alteridade ainda é, em si só, um desafio. Precisa-se avançar sobre o estranhamento às diferenças que povoam o imaginário dos atores escolar: alunos, professores, técnicos e responsáveis.

Quem recebe essa carga de impotência e isolamento são as crianças com deficiência, as quais estão no mundo, nas cidades, à beira dos rios, no campo, nas escolas. Estão nesses lugares, mas raramente efetivamente inseridas nesses espaços. As crianças com deficiência demoram mais tempo nas redes de papéis do que no livre exercício de atividades inclusivas. Implicitamente as crianças com deficiência, com dificuldades de aprendizagens, com hiperatividade, com transtornos, enfim, crianças com, significam algum tipo de problema, e, portanto, ficam na "nuvem" dos documentos que não se concretizam em ações inclusivas.

Interessante observar que o termo com não se constitui como sendo uma expressão que indique junto, isto é, um fazer tecido no compartilhamento de cada ação entre os envolvidos. Ao contrário, parece indicar uma adjetivação que separa e isola num rol pouco compreendido com agravo em sua própria identidade. Várias práticas pedagógicas e 
http://dx.doi.org/10.5902/1984686X44380

psicológicas que dizem lidar com tais crianças, buscam paradoxalmente, qualificar um lugar diferente para essas "crianças especiais".

É nesse contexto que muitas crianças "circulam" na cidade perambulando em inúmeras instituições especializadas em "dar jeito" e enquadrá-las em determinado perfil. Práticas ocupacionais, terapêuticas e clínicas recebem e encaminham crianças numa verdadeira "peregrinação" em busca do melhor tratamento ou da melhor adequação.

Enfim, evocando a mitologia grega por intermédio da cena de Procusto, que oferecia descanso aos viajantes, recorda-se que as práticas de inclusão não podem se configurar como a cama de ferro de Procusto, onde os viajantes devem "caber" exatamente a sua estrutura. As práticas de inclusão, e nesse caso aliadas as vivências artísticas, intencionam sempre acolher as diferenças de cada um no exercício de tolerância e respeito à dignidade de cada condição.

\section{Referências}

AMAZONAS. Lei Delegada no 81, de 18 de maio de 2007. Dispõe sobre a Secretaria de Estado de Cultura - SEC, definindo suas finalidades, competências e estrutura organizacional, fixando o seu quadro de cargos comissionados e estabelecendo outras providências. Disponível em:

http://diario.imprensaoficial.am.gov.br/diariooficial/consultaPublica.do;jsessionid=19AE7E5 9365A57A5D2C11696218E7FD8. Acesso em: 20 mar. 2014.

ARAÚJO, Marcos Vinícius de. et al. Formação de Professores e Inclusão Escolar de Pessoas com Deficiência: análise de resumos de artigos na base scielo.

Psicopedagogia, Pinheiros, vol. 27, Edição 84, p. 405-416, 2010.

ARAÚJO, Vania Carvalho de. Quando as crianças nos ensinam sobre a cidade. Educar em Revista. Curitiba, v. 35, n.75, p.319-334, maio/junho, 2019.

AZEVEDO, Nair Correia Salgado de; BETTI, Mauro. Pesquisa Etnográfica com crianças: caminhos teórico-metodológicos. Nuances: estudos sobre Educação, v. 25, n. 2, p. 291310, 2014.

BARDIN, Laurence. Análise de Conteúdo. São Paulo: Edições 70, 2016.

BAUMAN, Zygmunt. Modernidade Líquida. Rio de Janeiro: Zahar, 2001.

BAUMAN, Zygmunt. Confiança e Medo na Cidade. Rio de Janeiro: Zahar, 2009.

BELLONI, Maria Luiza Belloni. Infância, Mídias e Educação: revisitando o conceito de socialização. Perspectiva. Florianópolis, v. 25, n. 1, p. 41-56, jan.-jun., 2007. 
BEZERRA, Giovani Ferreira. A inclusão escolar de alunos com deficiência: uma leitura baseada em Pierre Bourdieu. Revista Brasileira de Educação, Rio de Janeiro, v. 22 n. 69, p. 475-497, abr.-jun., 2017.

BRASIL. Constituição da República Federativa do Brasil de 1988. Presidência da República. Disponível em:

http://www.planalto.gov.br/ccivil_03/constituicao/constituicao.htm. Acessado no dia 13 de maio de 2020.

BRASIL. Lei no 8.069, de 13 de julho de 1990. Dispõe sobre o Estatuto da Criança e do Adolescente e dá outras providências. Presidência da República. Disponível em:

http://www.planalto.gov.br/ccivil_03/leis/L8069.htm. Acessado no dia 13 de maio de 2020.

BRASIL. Lei n.13.005, de 25 de junho de 2014. Aprova o Plano Nacional de Educação PNE e dá outras providências. Diário Oficial da União, Brasília, DF., 26 de junho, 2014.

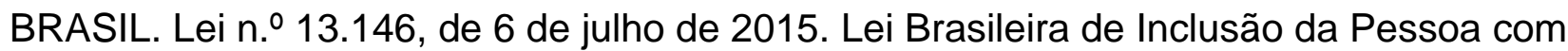
Deficiência (Estatuto da Pessoa com Deficiência). Presidência da República. Disponível em: http://www.planalto.gov.br/ccivil_03/_ato2015-2018/2015/lei/l13146.htm. Acessado no dia 13 de maio de 2020.

CAMARGO, Eder Pires de. Inclusão social, educação inclusiva e educação especial: enlaces e desenlaces. In.: Ciência e Educação, Bauru, v. 23, n. 1, p.1-6, 2017.

CARREIRA, Nélia Vieira. A criança e a cidade. Influência dos espaços verdes e áreas de jogo no desenvolvimento da criança. Dissertação-Lisboa: Universidade de Lisboa, 2016.

CHRISTENSEN, Pia.; O`BRIEN, Margaret. Children in the City. Home, Neighbourhood and Community. London: Routledge Falmer, 2003.

CIORNAI, Selma. (org). Percursos em Arteterapia. São Paulo: Summus, 2005.

COSTA, Claudia Regina Brandão Sampaio Fernandes. et al. Música e transformação no contexto da medida socioeducativa de internação. Psicologia: Ciência e Profissão, Brasília, v. 31, n. 4, p. 840-855, 2011.

ESPANHA, MINISTERIO DE EDUCACIÓN Y CIENCIA ESPAÑA - Organización de las Naciones Unidas para la Educación, la Ciencia y la Cultura. Conferencia Mundial sobre Necesidades Educativas Especiales: Acceso y calidad. España: Salamanca, 1994.

FALKENBACH; Atos Prinz; DREXSLER, Greice; WERLER, Verônica. A relação mãe/criança com deficiência: sentimentos e experiências. Ciência \& Saúde Coletiva, Rio de Janeiro, 13v (Sup 2), p.2065-2073, 2008.

FANIZZI, Caroline. A Educação e a procura por um laudo que diga quem és. Programa de Pós-Graduação em Educação (Dissertação de Mestrado) da Faculdade de Educação da Universidade de São Paulo. São Paulo, 2017. 
FONSECA, Karyne Cristine da. et al. Credibilidade e efeitos da música como modalidade terapêutica em saúde. Revista Eletrônica de Enfermagem, Goiânia, 8(3), p. 398-403, 2006.

GARÇÃO, Diogo Costa. Influência da dançaterapia na mobilidade funcional de crianças com paralisia cerebral hemiparética espástica. Motricidade, Vila Real, v.7, n.3, p. 3-9, julho, 2011.

GRIGOROWITSCHS, Tamara. Conceito "socialização" caiu em desuso? Uma análise os processos de socialização na infância com base em Georg Simmel e George H. Mead. Educação e Sociedade, Campinas, vol. 29, n. 102, p. 33-54, jan./abr. 2008.

HERMANN, Nadia. Hermenêutica e Educação. Rio de Janeiro: DP\&A, 2002.

HIGUCHI, Maria Inês Gasparetto; SILVA, Katiane. Entre a floresta e a cidade: percepção do espaço social de moradia em adolescentes. Psicologia para América Latina, São Paulo, n. 25, p. 5-23, 2013.

INEP - Instituto Nacional de Estudos e Pesquisas Educacionais Anísio Teixeira. Relatório do 2. Ciclo de Monitoramento das Metas do Plano Nacional de Educação - 2018. 2. ed. Brasília: Inep/MEC, 2019.

LACERDA JUNIOR, José Cavalcante; HIGUCHI, Maria Inês Gasparetto. A cidade pelas crianças. Rio de Janeiro: Autografia, 2019.

LACERDA JUNIOR, José Cavalcante. As imagens de Ciências na Cultura Infantil. Curitiba: Appris, 2018.

LOPES; Jader Janer Moreira; FERNANDES, Maria Lidia Bueno. A criança e a cidade: contribuições da Geografia da Infância. Educação. Porto Alegre, v.41, n. 2, p. 202-211, maio/agosto, 2018.

LUZ, Giordana Machado da; KUHNEN, Ariane. O uso dos espaços urbanos pelas crianças: explorando o comportamento do brincar em praças públicas. Psicologia: reflexão e crítica, Porto Alegre, v. 26, n. 3, p.552-560, 2013.

MATOS, Maria Almerinda de Souza; SOUZA, Danilo Batista de; OLIVEIRA, Jáima Pinheiro de. Acessibilidade e Educação Infantil: o processo de inclusão do público-alvo da educação especial em Manaus/Am. Revista Ibero-Americana de Estudos em Educação. Araraquara, v. 14, n. esp. 1, p. 760-744, abril, 2019.

MOLLO-BOUVIER, Suzanne. Transformação dos modos de socialização das crianças: uma abordagem sociológica. Educação e Sociedade, Campinas, vol. 26, n. 91, p. 391403, Mai./Ago. 2005

MOYSÉS, Maria Aparecida Affonso; COLARES, Cecília Azevedo Lima. Controle e medicalização na infância. Revista Desidades, Rio de Janeiro, n.1, v.1, dezembro, 2013. 
NOGUEIRA, Monique Andries. A música e o desenvolvimento da criança. Revista da UFG. Goiás, vol.5, n.2, p.22-25, dez. 2003.

PIRES, Flávia. Ser adulta e pesquisar crianças: explorando possibilidades metodológicas na pesquisa antropológica. Revista de Antropologia, v. 50, n. 1, p. 225-270, jun. 2007.

RASMUSSEN, Kim. Places for Children - Children's Places. Childhood, v. 11, n. 2, p. 155-173, 2004.

SANTOS, Thanires Rafaele Menezes Soares dos.; CAVALCANTE, Tamires Barradas; SILVA JUNIOR, João Ferreira. Terapia musical em pacientes com distúrbios da consciência: uma revisão integrativa. Cadernos Brasileiros de Terapia Ocupacional, São Carlos, vol.27 n.4, p. 873-884, out./dez. 2019.

SARMENTO, Manuel Jacinto. Apresentação. Cadernos de Pesquisa em Educação. Vitória, ES. a. 16, v. 21, n. 49, janeiro - junho, 2019.

SILVA, Tomaz Tadeu da (org.). Identidade e Diferença: a perspectiva dos Estudos Culturais. 3.ed. Editora Vozes: Petrópolis: RJ, 2004.

SILVEIRA, Flávia Furtado; NEVES, Marisa Maria Brito da Justa. Inclusão escolar de crianças com deficiência múltipla: concepções de pais e professores. Psicologia: teoria e pesquisa. Brasília, vol.22, n.1, p. 79-88, janeiro/abril, 2006.

SIMÕES, André; ATHIAS, Leonardo; BOTELHO, Luanda. (orgs.). Panorama Nacional e Internacional da Produção de Indicadores Sociais: grupos populacionais específicos e uso do tempo. Instituto Brasileiro de Geografia e Estatística: Rio de Janeiro, 2018.

SCHROEDER, Silvia Cordeiro Nassif. A arte como linguagem: um olhar sobre as práticas na educação infantil. Leitura: teoria \& prática, vol. 30, n. 58, p.77-85, 2012.

TEIXEIRA-MACHADO, Lavínia. Dançaterapia no autismo: um estudo de caso.

Fisioterapia e Pesquisa, São Paulo, vol.22, n.2, p. 205-211, abril-junho, 2015.

TROCOLI, Edla.; BONFATTI, Sabrina. Educação Inclusiva. 1.ed. Brasília: Editora Alumnus, 2018.

TONDATTI, Paula Chadi. A música enquanto instrumento terapêutico na resposta clínica da criança em unidade de terapia intensiva pediátrica. Programa de PósGraduação em Enfermagem (Dissertação de Mestrado) da Faculdade de Medicina da Universidade Estadual Paulista, 120 f. Botucatu, 2011.

UNESCO. Declaração mundial sobre educação para todos (Conferência de Jomtien). Tailândia, 1990. Disponível em: https://www.unicef.org/brazil/declaracao-mundial-sobreeducacao-para-todos-conferencia-de-jomtien-1990. Acessado no dia 21 de março de 2020. 
http://dx.doi.org/10.5902/1984686X44380

VASCONCELOS, Maria Goreth da Silva. Políticas Públicas e atendimento educacional: o papel da Casa Mamãe Margarida junto a crianças e adolescentes em situação de acolhimento e vulnerabilidade social. Programa de Pós-Graduação em Educação (Dissertação de Mestrado) da Faculdade de Educação da Universidade Federal do Amazonas. 171 f., Manaus, 2015.

VIEIRA, Camila de Carvalho. Contribuições da Arte e do Professor Arteterapeuta para a Educação Inclusiva. Revista Educação, Artes e Inclusão, Florianópolis, vol. 13, n.2, p.136-152, mai./ago., 2017.

VITALINO, Célia Regina. Análise da necessidade de preparação pedagógica de professores de cursos de licenciatura para inclusão de alunos com necessidades educacionais especiais. Revista Brasileira de Educação Especial. vol.13, n.3, p.399414. 2007.

\section{Correspondência}

José Cavalcante Lacerda Junior - Instituto Federal de Educação, Ciência e Tecnologia do Amazonas, IFAM - Campus Manaus Distrito Industrial, Avenida Governador Danilo Areosa, 1731, Distrito Industrial I, Manaus, Amazonas - Brasil.

CEP: $69075-351$

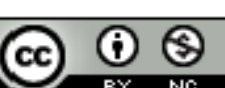

4.0 International (CC BY-NC 4.0) 